\title{
Relationship between a College Student's SNS Sunfull-Writing Experience (writing positive comments) and Ego-resilience / Adaptation to College Life
}

\author{
Byoung-Chul Min, Kyoung-Sook Oh, Sang-Yong Yun \\ Sunfull Foundation, Kookje University, Myongji University \\ geb1568@daum.net
}

\begin{abstract}
The purpose of this study is to investigate the relationship between a college student's SNS Sunfull-writing experience (writing positive comments on a social networking service) to egoresilience and college life adjustment.

For this purpose, we surveyed 158 university undergraduates in city $G$ of Gyeonggi Province, ${ }^{1}$ South Korea. The results are: First, there was high ego-resilience among students who had significant levels of Sunfull-writing experience, made significant effort to do Sunfull-writing, and who recognized that they can benefit from being educated about Sunfull-writing (being taught the importance of writing Sunfull comments and to be able to practice writing positive comments in a classroom setting). Second, students who put significant effort to do Sunfullwriting were better at adapting to college life. Third, the more a student tried to write Sunfull comments and felt the need for Sunfull -writing education, the higher the college student's egoresilience was. And fourth, the greater the experience of Sunfull-writing, the better the student was able to adapt to college life. Our conclusion is that the experience of Sunfull-writing can help the ego-resilience and adaptation to college life of students.
\end{abstract}

Keywords: Sunfull Internet Peace Movement, College Student, Ego-Resilience, College Students' Life Adjustment.

\section{Introduction}

The use of Social Networking Services (hereinafter, SNS) is wide spread amongst college students, attracting interest as a tool that enables college students to acquire new knowledge, make more personal connections, and create and maintain social networks. These SNSs provide many positive effects including broadening the interpersonal relationships of college students and providing information and technology for employment and entrepreneurship. On the other hand, we cannot avoid the various social problems such as verbal violence like slander, abuse, and socio-phobia issues caused by SNS, which guarantees anonymity. Especially malicious internet comments can be considered as an important social problem to be solved because it annihilates the identity of an individual and causes depression, socio-phobia, and even suicide, all of which have great influence on the lives of college students.

College students are participating in a number of club activities that use leisure to cultivate their character and broaden human relationships in college. These club activities can provide

\footnotetext{
${ }^{1}$ Article history:

Received (April 15, 2019), Review Result (May 12, 2019), Accepted (June 8, 2019)
} 
college students with a variety of benefits such as temporary stress reduction, as well as career guidance, and can have a positive impact on university life[1]. In addition, there is the advantage to raise ego-resilience (there being stressed less or not being influenced by increasing stressful situations such as a negative life event or a dangerous environment, and the ability to quickly recover from adversity and shock by coping with change and adversity that can cope with the adaptation of the school life flexibly[2]).

Currently, there are various types of clubs such as volunteer clubs, cultural arts clubs, and academic education clubs. Among them, the club activities to develop the SNS Sunfull Campaign are aimed at raising the community spirit of students, raising leadership life skills[3] increasing the sociality and self-esteem of students[4], and raising the adaptation to school life[5]. The Sunfull Internet Peace Movement counters abusive comments on the internet; Sunfull's activity has been conducted primarily for elementary, middle and high school students throughout the country. As a new concept of community service suitable for solving youth problems and the adaptation of school life emerges, now the movement is being practiced not only by college students, but also by local communities.

The purpose of this study is to investigate the relationship between SNS Sunfull-writing experience, and ego-resilience/adaptation to college life by college students. The aim is to raise the importance of participation experiences in college Sunfull Foundation activities and to recognize the necessity of promoting participation of correct internet comment culture in schools and local communities.

The research issues are as follows.

First, does ego-resilience of college students vary according to the experience of SNS Sunfull-writing?

Second, does the level of college students' adaptation to college life vary according to the SNS Sunfull-writing experience?

Third, what is the relationship between SNS Sunfull-writing skill, ego-resilience, and college life adaption level?

\section{Research Method}

\subsection{Subjects}

The subjects of this study were 158 female students (First grade: 65 persons, $41.4 \%$, second grade: 93 persons: $58.9 \%$ ) attending a Korean university ( $\mathrm{K}$ college located in Gyeonggi Province, South Korea).

\subsection{Research Tools}

\section{1) Experience with SNS Sunfull-writing}

In order to investigate the real condition of the experiences of college students' Sunfullwriting on the internet, the researchers wrote with reference to a questionnaire from a 2011 survey conducted by the Sunfull Foundation. The questionnaire for this study consisted of seven questions about internet comments and Sunfull experience, the effort of Sunfull-writing, the effects of Sunfull, and education level. In this paper, the term 'Sunfull' refers to comments of encouragement and love that are logical, persuasive, positive, hopeful, and caring about a specific issue. "Sunfull-writing" refers to giving 'Sunfull', the comment of love and encouragement to the victim who is suffering from malicious comments for a specific issue on the internet[6] 


\section{2) Ego-resilience}

To measure ego-resilience, we employed the scale of Eun-Ok Jung[7]. This scale comprised 3 sub-factors, 16 items, and a Likert 5-point scale. The overall reliability of the ego-resilience evaluation using Cronbach's $\alpha$ measurement tool, coefficient was .834 , positivity for future orientation .899 , emotional regulation .739 , diversity of interests and enthusiasm .797 .

\section{3) Adaptation to college life}

The scale used by Ji-Hyun Choi[8] was used to measure university life adaptation. The scale consisted of 5 sub-factors, 25 items, and Likert 5-point scale. The overall reliability using Cronbach $\alpha$ 's measurement tool, coefficient was .851, academic adaptation .670 , social adaptation .640, emotional adaptation .791, physical adaptation .624, and college life attachment .663 .

\subsection{Data collection and analysis}

This study distributed a total of 180 questionnaires to students attending $\mathrm{K}$ college from October 15 to October 20, 2018, of which 174 were collected, and 158 were analyzed (16 questionnaires consisting of many unanswered or inadequate responses were not included in the analysis).

From the retrieved data, we performed reliability coefficients, t-test, one-way analysis of variance (posterior tests: Duncan) and correlation analysis adopting the SPSS WIN 21.0 program.

\section{Results and Interpretation}

\subsection{The differences in ego-resilience according to the Sunfull-writing experience}

As a result of investigating the variations in ego-resilience of college students by their Sunfull-writing experience and Sunfull-writing effort, and the need of Sunfull-writing education showed substantial disparities in ego-resilience as indicated in Table 1. For each variable, the results are as follows.

First, students who reported Frequently engaging in Sunfull-writing showed higher egoresilience than those students who had Sometimes, Rarely, or Never $(F=3.23, p<.05)$ engaged in Sunfull-writing. Also, in emotional regulation and diversification of interest among subaspects of ego-resilience, the students who answered Frequently indicated higher grades than those who responded Rarely $(\mathrm{F}=2.95, \mathrm{p}<.05, \mathrm{~F}=4.58, \mathrm{p}<.01)$. Students who reported Often or Regularly writing Sunfull comments showed higher points in ego-resilience $(t=-3.03$, $\mathrm{p}<.01)$, positive future orientation $(\mathrm{T}=-2.74, \mathrm{p} 0.01)$, and diversity of interest $(\mathrm{t}=-3.85, \mathrm{p}$ $<.001)$ than those who answered Never. The students who answered that Sunfull-writing education is needed So much showed higher levels in ego-resilience $(\mathrm{F}=5.55, \mathrm{p}<.01)$, positive future orientation $(\mathrm{F}=4.62, \mathrm{p}<.05)$, emotional control $(\mathrm{F}=3.10, \mathrm{p}<.05)$, and diversity of interest and enthusiasm $(\mathrm{F}=6.68, \mathrm{p}<.01)$ than those who answered that education is needed $\mathrm{A}$ little or Never. 
Table 1. Differences in Ego-resilience according to SNS Sunfull-Writing Experience

\begin{tabular}{|c|c|c|c|c|c|c|}
\hline & & $N$ & $\begin{array}{c}\text { Positive } \\
\text { future } \\
\text { orientation }\end{array}$ & $\begin{array}{l}\text { Emotion } \\
\text { control }\end{array}$ & $\begin{array}{l}\text { Diversity of } \\
\text { interest and } \\
\text { enthusiasm }\end{array}$ & $\begin{array}{l}\text { Ego- } \\
\text { resilience }\end{array}$ \\
\hline \multirow{5}{*}{$\begin{array}{l}\text { Sunfull-writing } \\
\text { experience }\end{array}$} & Never & 42 & $3.47(.63)$ & $3.24(.61) \mathrm{ab}$ & 3.43(.64)ab & $3.40(.53) \mathrm{a}$ \\
\hline & Rarely & 36 & $3.43(.63)$ & $3.10(.50) \mathrm{a}$ & $3.28(.45) \mathrm{a}$ & $3.27(.44) \mathrm{a}$ \\
\hline & Sometimes & 56 & $3.59(.60)$ & $3.05(.48) \mathrm{a}$ & $3.60(.58) b c$ & $3.42(.45) \mathrm{a}$ \\
\hline & Frequently & 24 & $3.80(.70)$ & $3.41(.60) \mathrm{b}$ & $3.79(.61) \mathrm{c}$ & $3.67(.53) b$ \\
\hline & $F$ & & 1.96 & $2.95^{*}$ & $4.58^{* *}$ & $3.23^{*}$ \\
\hline \multirow{3}{*}{$\begin{array}{l}\text { Effort for Sunfull- } \\
\text { writing }\end{array}$} & Never & 66 & $3.39(.64)$ & $3.11(.56)$ & $3.30(.60)$ & $3.28(.51)$ \\
\hline & $\begin{array}{l}\text { Often, } \\
\text { regularly }\end{array}$ & 92 & $3.67(.61)$ & $3.21(.54)$ & $3.66(.55)$ & $3.52(.46)$ \\
\hline & $t$ & & $-2.74 * *$ & -1.10 & $-3.85^{* * *}$ & $-3.03 * *$ \\
\hline \multirow{4}{*}{$\begin{array}{l}\text { Need of Sunfull- } \\
\text { writing education }\end{array}$} & Never & 35 & $3.54(.61) \mathrm{a}$ & $3.25(.47) \mathrm{ab}$ & $3.38(.51) \mathrm{a}$ & $3.39(.41) \mathrm{a}$ \\
\hline & A little & 87 & $3.45(.60) \mathrm{a}$ & $3.07(.45) \mathrm{a}$ & $3.44(.54) \mathrm{a}$ & $3.33(.43) \mathrm{a}$ \\
\hline & So much & 36 & $3.82(.69) \mathrm{b}$ & $3.31(.77) \mathrm{b}$ & $3.82(.71) \mathrm{b}$ & $3.65(.64) \mathrm{b}$ \\
\hline & $F$ & & $4.62^{*}$ & $3.10^{*}$ & $6.68^{* *}$ & $5.55^{* *}$ \\
\hline
\end{tabular}

\subsection{Difference in adaptation of college life by the Sunfull-writing experience}

As illustrated in Table 2, the undergraduates that Often or frequently spend time on Sunfullwriting were more likely to comply with college life than those who Rarely spend time on Sunfull-writing $(\mathrm{t}=-3.01, \mathrm{p}<.01)$. And the juniors who engaged in Sunfull-writing Often or frequently had higher scores for social adaptation $(\mathrm{t}=-3.17, \mathrm{p}<.01)$, emotional adaptation $(\mathrm{t}=$ $-2.12, \mathrm{p}<.05)$, and physical adaptation $(\mathrm{t}=-2.95, \mathrm{p}<.01)$ in the sub-variables as well had higher score than those who reported Rarely doing Sunfull-writing. There was no meaningful difference in the need for the experience of Sunfull-writing and Sunfull-writing education.

Table 2. Differences in Adaptation to College Life according to SNS SunfullWriting Experience

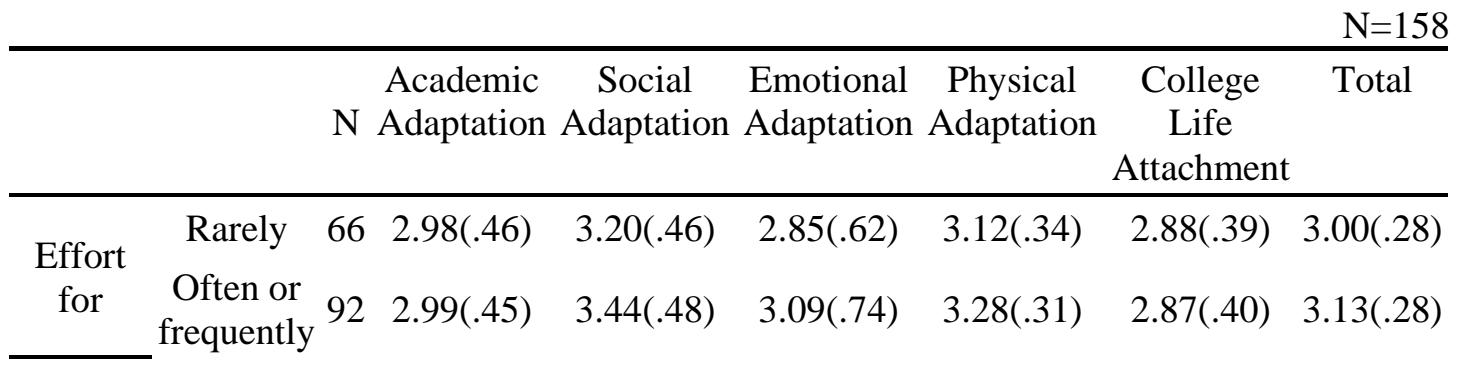




\begin{tabular}{|c|c|c|c|c|c|c|c|}
\hline $\begin{array}{c}\text { Sunfull- } \\
\text { writing }\end{array}$ & $\mathrm{t}$ & -.17 & $-3.17 * *$ & $-2.12^{*}$ & $-2.95 * *$ & .17 & $-3.01 * *$ \\
\hline
\end{tabular}

\subsection{The relationship between college students' SNS Sunfull-writing experience and ego- resilience/adaptation to college life}

As a result of the analysis, the effort to write Sunfull and the recognition of the necessity for Sunfull-writing education had a significant positive correlation with ego-resilience. The more the effort to write Sunfull $(\mathrm{r}=0.296, \mathrm{p}<0.001)$ and the higher the perceived necessity of Sunfull-writing education $(r=0.268, p<0.001)$, the higher the ego-resilience of college students was. Among the sub-variables of ego-resilience, interest and attention were positively correlated with all variables such as Sunfull-writing experience level, effort for Sunfull-writing, and necessity recognition of Sunfull-writing education. And the variable indicating positivity for the future showed a positive correlation with the effort for Sunfull-writing and recognition of the necessity for Sunfull-writing education.

Next there was a significant positive correlation between the Sunfull-writing experience level and the college life adaptation total $(\mathrm{r}=0.163, \mathrm{p}<0.05)$. In other words, it was confirmed that the higher the Sunfull-writing experience, the better the adaptation to college life was. In the sub-variables of college life adaptation, the Sunfull-writing experience level was positively correlated to physical adaptation; effort for Sunfull-writing was positively correlated to social adaptation; and necessity recognition of Sunfull-writing education was positively correlated to social adaptation and college attachment.

\section{Table 3. The relationship between college students' SNS Sunfull-writing experience and ego-resilience/adaptation to college life}

\begin{tabular}{cccc}
\hline & $\begin{array}{c}\text { Sunfull-writing } \\
\text { experience level }\end{array}$ & $\begin{array}{c}\text { Effort for Sunfull- } \\
\text { writing }\end{array}$ & $\begin{array}{c}\text { Necessity } \\
\text { recognition of S-F } \\
\text { writing education }\end{array}$ \\
\cline { 2 - 4 } Positivity for the future & .063 & $.245^{* *}$ & $.272^{* * *}$ \\
Interest and attention & $.213^{* *}$ & $.360^{* * *}$ & $.286^{* * *}$ \\
Ego-resilience total & .153 & $.296^{* * *}$ & $.268^{* * *}$ \\
\hline Emotional adaptation & .132 & .153 & .020 \\
Social adaptation & .031 & $.194^{*}$ & $.244^{* *}$ \\
Physical adaptation & $.254 * *$ & .126 & .007 \\
College attachment & .130 & .055 & $.292^{* * *}$ \\
College life adaptation & $.163^{*}$ & .008 & .153 \\
total & & &
\end{tabular}

\section{Conclusion}

The purpose of this research was to probe the characteristics in ego-resilience and college life adaptation of college students by the experience of SNS Sunfull-writing, and to explore the 
relationship between the SNS Sunfull-writing experience and ego-resilience and college life change. The results are as follows.

First, the students who have experienced high levels of Sunfull-writing experience, the students who frequently put effort in Sunfull-writing, and the students who felt the necessity of Sunfull-writing education were more ego-resilient. In particular, there showed considerable discrepancies in emotion control and diversification of interest and enthusiasm.

Second, the students who frequently endeavored to promote their Sunfull-writing were eminently compliant to college life. Especially, it presented a significant gain in emotional adaptation, social adaptation, and physical adaptation.

Third, it was found that the more the effort for Sunfull-writing, the higher the recognition of the necessity of Sunfull-writing education and the higher the ego-resilience of the college students was. Also, it was found that the higher the experience level of Sunfull-writing, the better the adaptation to college life was. This result implies that the experience of Sunfullwriting can contribute to the ego-resilience of college students and the adaptation of university life.

This is coherent with the results of Ji-Youn Woo et al.[1], Dong-Il Min[2], and Wan-Su Kim[9], which suggest that club activities and volunteer activities enhance ego-resilience and enhance school life adjustment in adolescents.

The results demonstrated that the target population of undergraduate students received more Sunfull-writing experience and made significant effort to do Sunfull-writing using SNS, and showed that these experiences and perceptions have a positive correlation with ego-resilience of college students and adaptation to college life. This seems to result from the combination of encouraging language pursued in the Sunfull Internet Peace Movement, a pleasant language, and the intention of the loving mind plus the motivation of the students voluntarily taking part in the activities. Therefore, it is crucial to develop a lot of club activities in which college students make voluntary participation while having an explicit purpose.

However, because we sampled only the college students in a certain area in carrying out this study, it may be a little troublesome to generalize the research results to students nationwide. Future research suggests that the study needs to broaden the target population nationwide.

\section{References}

[1] J. Y. Woo, H. K. Park, H. G. Lee. "The Casual Relationship between Sports Enjoyment, Friendship Quality of University Students Sports Club and College Life Satisfaction”. Journal of Sport and Leisure Studies (2014), Vol.0, No.56, pp.581-593.

[2] D. I. Min. "The Effects of Family Strengths, School Life Health and Ego-Resilience on Mental Health of Adolescents". Department of Education Graduate School Inha University (2007).

[3] B. C. Min, C. S. Lee, S. Y. Yun, G. I. Park, K. S. Oh. "A Study on the influence of Sunfull Voluntary Activities on the sense of community of the Youth". Journal of the Korea Academia-Industrial Cooperation Society (2018), Vol.19, No.2, pp.374-376.

[4] M. B. Jang, K. S. Oh, S. Y. Yun, W. G. Gung. "Difference on Social Development and Self-Esteem following to the Experience of the Volunteering". Journal of the Korea Academia-Industrial Cooperation Society (2017), Vol.18, No.2, pp.603-605.

[5] B. C. Min, K. S. Oh. "A Study of the Effects of Youth Sunfull Volunteering Participation on School Adjustment”. Journal of the Korea Academia-Industrial Cooperation Society (2018), Vol.19, No.2, pp.384-386.

[6] http://www.sunfull.or.kr 
[7] E. O. Jung. "A Validation of Psychological Resilience Scale”. Dept. of Psychology Graduate School of Chonbuk National University (2006).

[8] J. Y. Choi. "Effects of emotional intelligence and ego-resilience on adjustment to college life". Yonsei University (2008).

[9] W. S. Kim. "A Study on the Influence of Youth Volunteer Experience on School Life Adaptation and Leadership Life Skills". Department of Social Welfare Graduate School of Seoul Christian University (2018).

\section{Authors}

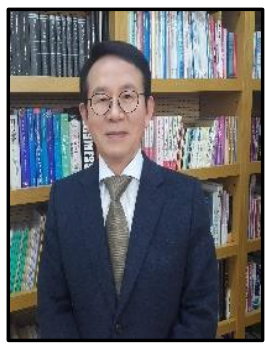

Byoung-Chul Min, Ed.D.

Author's profile:

Distinguished Professor, Hanyang University, South Korea

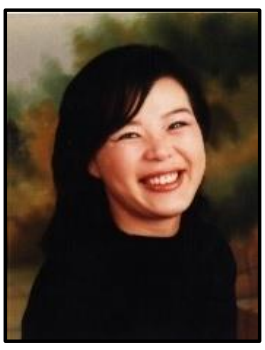

Kyeong-Sook Oh

Author's profile:

Professor, Kookje University, South Korea

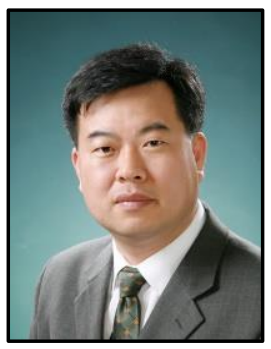

\section{Sang-Yong Yun}

Author`s profile:

Student, Myongji University, South Korea 
Relationship Between a College Student's SNS Sunfull-Writing Experience (writing positive comments) and Egoresilience / Adaptation to College Life 